\title{
Electrochemical generation of 2,3-oxazolidinone glycosyl triflates as an intermediate for stereoselective glycosylation
}

\author{
Toshiki Nokami ${ }^{1}$, Akito Shibuya ${ }^{1}$, Yoshihiro Saigusa ${ }^{1}$, Shino Manabe ${ }^{\star 2}$, \\ Yukishige Ito ${ }^{2,3}$ and Jun-ichi Yoshida ${ }^{* 1}$
}

\section{Letter}

\section{Address:}

${ }^{1}$ Department of Synthetic Chemistry and Biological Chemistry, Kyoto University, Nishikyo-ku Kyoto 615-8510 Japan, ${ }^{2}$ Advanced Science Institute, RIKEN, Hirosawa, Wako, Saitama 351-0198, Japan and ${ }^{3}$ ERATO JST, Hirosawa, Wako, Saitama 351-0198, Japan

Email:

Shino Manabe* - smanabe@riken.jp; Jun-ichi Yoshida* -

yoshida@sbchem.kyoto-u.ac.jp

* Corresponding author

Keywords:

amino sugar; anomerization; electrochemical oxidation; glycosylation; thioglycoside

\begin{abstract}
Glycosyl triflates with a 2,3-oxazolidinone protecting group were generated from thioglycosides by low-temperature electrochemical oxidation. The glycosyl triflates reacted with alcohols to give the corresponding glycosides $\beta$-selectively at low temperatures. However, $\alpha$-selectivity was observed in the absence of base at elevated reaction temperatures. In situ generated triflic acid promotes the isomerization of $\beta$-products to $\alpha$-products.
\end{abstract}

\section{Introduction}

Stereoselective formation of glycosidic linkages is the key issue in oligosaccharide synthesis, because both 1,2-trans and 1,2-cis aminoglycosides are ubiquitous in biologically active oligosaccharides [1-5]. The 1,2-trans aminoglycosides, which are found in Nod factor [1] and lipid A [2], can be easily prepared by protecting the 2-amino group with phthaloyl or carbamate groups [6]. On the other hand, 1,2-cis glycosidic linkages are still difficult to make with perfect stereoselectivity. Although 2-azido-substituted glycosyl donors are commonly used for the preparation of 1,2-cis glycosidic linkages of amino sugars [7,8],

the selectivity highly depends on the nature of the glycosyl acceptors and reaction conditions. In the last decade, 2,3-oxazolidinone protected 2-amino-2-deoxy-glycosides have been developed as glycosyl donors for the stereoselective synthesis of amino sugars [9-24]. These glycosyl donors afford the corresponding glycosides in a 1,2-trans or 1,2-cis selective manner by action with various types of glycosyl acceptors. However, it is still uncertain whether glycosyl triflate intermediates [25], which were detected by NMR, play an important role in the stereoselective formation of both $\alpha$ - and $\beta$-isomers. 
We have developed an electrochemical method to generate and accumulate highly reactive glycosyl triflates by low-temperature electrochemical oxidation of thioglycosides [26-30]. Although Kerns and Ye have already reported a chemically generated glycosyl triflate equipped with an acetylated 2,3oxazolidinone protecting group [11,19], we envisioned that the electrochemically generated glycosyl triflate with a 2,3-oxazolidinone protecting group could be a useful intermediate to reveal stereoselectivity in glycosylations via glycosyl triflate intermediates. In this paper, we report the generation, accumulation, and characterization by low-temperature NMR analyses, of the corresponding glycosyl triflates. Electrochemical glycosylation of the thioglycoside donor with 2,3-oxazolidinone protecting group gave both 1,2-trans linkages in the presence of a base at low temperatures and 1,2-cis glycosidic linkages in the absence of a base at elevated temperatures.

\section{Results and Discussion}

We began by conducting the electrochemical oxidation of 2,3oxazolidinone thioglycosides $\mathbf{1 a}-\mathbf{1 c}$ in the absence of a glycosyl acceptor at low temperatures in order to generate and accumulate the corresponding glycosyl triflates (Scheme 1). Lowtemperature NMR measurements of the anodic solution were carried out to confirm the structure of the glycosyl triflates. For example, the anodic solution obtained by the electrochemical oxidation of thioglycoside 1a (4 mA, $1 \mathrm{~h})$ exhibited a single set of peaks for glycosyl triflate 2a in the ${ }^{1} \mathrm{H}$ NMR spectrum at $-80{ }^{\circ} \mathrm{C}$ (Figure 1). In contrast to the previous reports by Kerns and $\mathrm{Ye}$, the corresponding $\beta$-triflate was not observed under these conditions $[11,19]$. The small coupling constant of the anomeric proton $(J=2.1 \mathrm{~Hz})$ indicates $\alpha$-configuration of the anomeric triflate. The ${ }^{1} \mathrm{H}$ and ${ }^{13} \mathrm{C}$ NMR chemical shifts of the anomeric protons and carbons of glycosyl triflates $\mathbf{2} \mathbf{a}-\mathbf{c}$ are listed in Table 1. In all cases, the starting thioglycosides 1a-c were quantitatively converted to the corresponding glycosyl triflates $\mathbf{2 a}-\mathbf{c}$, which have $\alpha$-configuration of the anomeric triflate. Although the chemical shift of the anomeric proton $\mathrm{H}-1$ of glycosyl triflate 2a appears at a lower chemical shift

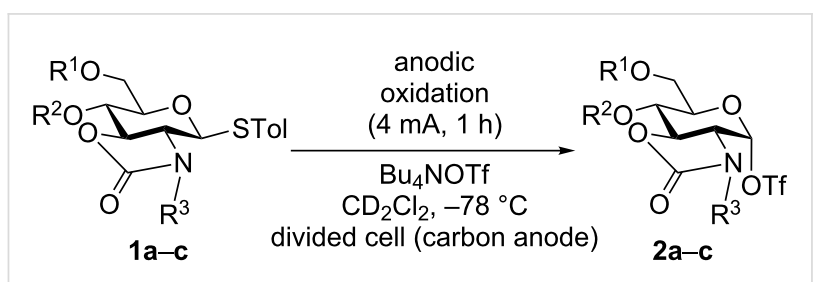

1a, 2a: $R^{1}=R^{2}=R^{3}=A c$

1b, 2b: $\mathrm{R}^{1}=\mathrm{Bn}, \mathrm{R}^{2}=\mathrm{ClCH}_{2} \mathrm{CO}, \mathrm{R}^{3}=\mathrm{Bn}$

1c, $2 c: R^{1}=R^{2}=R^{3}=B n$

Scheme 1: Electrochemical conversion of thioglycosides to glycosyl triflates.
(6.89 ppm) than those of glycosyl triflates $\mathbf{2 b}$ (5.97 ppm) and $\mathbf{2 c}$ (5.95 ppm), the chemical shift of the anomeric carbon is around $100 \mathrm{ppm}$ in all cases and the corresponding cross peaks of the anomeric protons and carbons were observed in HMQC spectra.

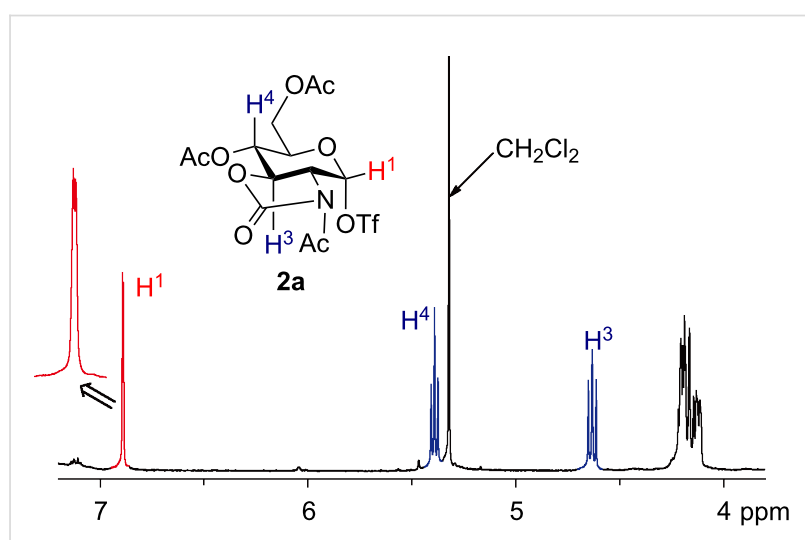

Figure 1: ${ }^{1} \mathrm{H}$ NMR spectrum of glycosyl triflate $2 \mathrm{a}$.

Table 1: ${ }^{1} \mathrm{H}$ - and ${ }^{13} \mathrm{C}$ NMR chemical shifts of the anomeric proton and carbon of glycosyl triflates $2 \mathbf{a}-\mathbf{c}$.

\begin{tabular}{llll} 
entry & glycosyl triflate & $\begin{array}{l}{ }^{1} \mathrm{HNMR} \\
{\left[\delta(\mathrm{ppm})^{\mathrm{a}}, J(\mathrm{~Hz})^{\mathrm{b}}\right]}\end{array}$ & $\begin{array}{l}{ }^{13} \mathrm{C} \mathrm{NMR} \\
{\left[\delta(\mathrm{ppm})^{\mathrm{a}}\right]}\end{array}$ \\
\hline 1 & 2a & $6.89,2.1^{\mathrm{c}}$ & 99.9 \\
2 & 2b & 5.97, singlet & 99.9 \\
3 & 2c & 5.95, singlet & 100.7 \\
\hline
\end{tabular}

${ }^{a}$ chemical shift; ${ }^{b}$ coupling constant; ${ }^{c}$ doublet.

Using electrochemically generated glycosyl triflate $\mathbf{2 a}$, the stereoselectivity of the glycosylation was investigated by the addition of five equiv of various alcohols (Table 2). In accordance with our previous results [26,29], high $\beta$-selectvity was observed with highly reactive alcohols (Table 2, entries 1 and 2). On the other hand, less nucleophilic alcohols, such as benzyl alcohol and $\mathrm{CF}_{3} \mathrm{CH}_{2} \mathrm{OH}$, gave the corresponding glycosides in lower $\beta$-selectivity than methanol or ethanol (Table 2, entries 3 and 4) [31].

Next, we examined the electrochemical activation of thioglycoside $\mathbf{1 a}$ to generate glycosyl triflate $\mathbf{2 a}$ in the presence of glycosyl acceptor 7 . In order to improve the yield and the stereoselectivity of glycosylation, we examined the effects of the reaction temperature and base (Table 3). Although poor $\beta$-selectivity and yield were observed at low temperatures in the absence of a base (Table 3, entry 1), the addition of an organic base such as 2,6-di-tert-butyl-4-methylpyridine (DTBMP), significantly improved the $\beta$-selectivity and yield (Table 3 , entry 2). In both cases small amounts of the $\alpha$-isomers of the 
Table 2: Glycosylation of electrochemically generated glycosyl triflate 2a.

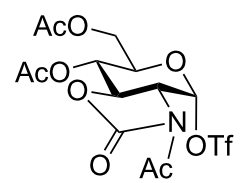

$2 a$

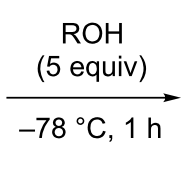

$8^{\circ} \mathrm{C}, 1 \mathrm{~h}$

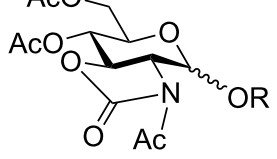

3-6

\begin{tabular}{lll}
\hline entry & $\mathrm{ROH}$ & product: yielda ${ }^{\mathrm{a}}$, ratio $(\alpha \text { to } \beta)^{\mathrm{b}}$ \\
\hline 1 & $\mathrm{MeOH}$ & 3: $76 \%(<1$ to $>99)$ \\
2 & $\mathrm{EtOH}$ & 4: $71 \%(<1$ to $>99)$ \\
3 & $\mathrm{BnOH}$ & 5: $89 \%(9$ to 91$)$ \\
4 & $\mathrm{CF}_{3} \mathrm{CH}_{2} \mathrm{OH}$ & 6: $82 \%(15$ to 85$)$ \\
\hline
\end{tabular}

aisolated yields; ${ }^{b}$ determined by ${ }^{1} \mathrm{H}$ NMR.

starting thioglycoside $\mathbf{9}$ and glucal $\mathbf{1 0}$ were obtained as byproducts (Table 3, entries 1 and 2). The yield was further increased and the formation of byproducts was suppressed by raising the reaction temperature to $0{ }^{\circ} \mathrm{C}$ (Table 3 , entry 3 ). On the other hand, the corresponding $\alpha$-isomer of disaccharide $8 \boldsymbol{\alpha}$ was obtained as a major product together with the anomerized donor 9 when the reaction was performed at $0{ }^{\circ} \mathrm{C}$ in the absence of DTBMP (Table 3, entry 4). These anomerizations may be caused by the endocyclic cleavage reaction [22-24], which is often observed for pyranosides with a 2,3-trans carbamate group, under acidic conditions. The yield of disaccharide $\mathbf{8}$ was improved by raising the temperature to $0{ }^{\circ} \mathrm{C}$ after the completion of electrolysis at $-78{ }^{\circ} \mathrm{C}$ (Table 3 , entry 5). The fact that disaccharide 8 was obtained in higher yields (59\% to $78 \%)$ and that only a trace amount of $\alpha$-isomer 9 (4\%) was obtained strongly suggests that the isomerization of thioglycoside donor 1a occurs during the electrolysis at $0{ }^{\circ} \mathrm{C}$. It is noteworthy that the $\alpha$ - and $\beta$-glycosides could be selectively prepared from the same glycosyl donor with a 2,3-trans carbamate group, simply by changing the reaction conditions.

In order to confirm that the anomerization of $\mathbf{8} \boldsymbol{\beta}$ to $\mathbf{8 \alpha}$ could take place under the reaction conditions, we examined the acidmediated isomerization of the $\beta$-isomer of disaccharide $\mathbf{8} \boldsymbol{\beta}$ to the $\alpha$-isomer $8 \alpha$ (Scheme 2). Triflic acid (TfOH) must be generated in situ by the reaction of glycosyl triflate $\mathbf{2 a}$ with alcohols. Thus, TfOH (1.0 equiv) and tetrabutylammonium triflate ( $\mathrm{Bu}_{4} \mathrm{NOTf}$ ) (5.0 equiv), which was used as a supporting electrolyte for electrolysis, were added to a $\mathrm{CH}_{2} \mathrm{Cl}_{2}$ solution of the $\beta$-isomer of disaccharide $8 \boldsymbol{\beta}$ at $0{ }^{\circ} \mathrm{C}$. After stirring at $0{ }^{\circ} \mathrm{C}$ for $1 \mathrm{~h}$, the reaction was quenched by the addition of $\mathrm{Et}_{3} \mathrm{~N}$. The $\alpha$-isomer of the disaccharide $8 \boldsymbol{\alpha}$ was obtained in $83 \%$ yield as a single isomer. This experiment shows that the $\alpha$-product $8 \boldsymbol{\alpha}$ is the isomerization product of the $\beta$-isomer $\mathbf{8} \boldsymbol{\beta}$ as a result of endocyclic cleavage, as shown in Scheme 2.

Table 3: Electrochemical glycosylation in the presence of glycosyl acceptor.

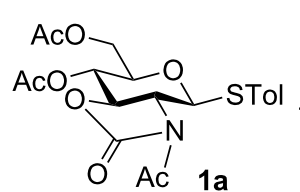

(1.2 equiv)

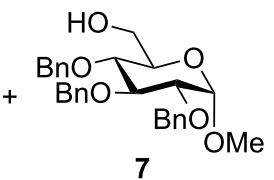

7

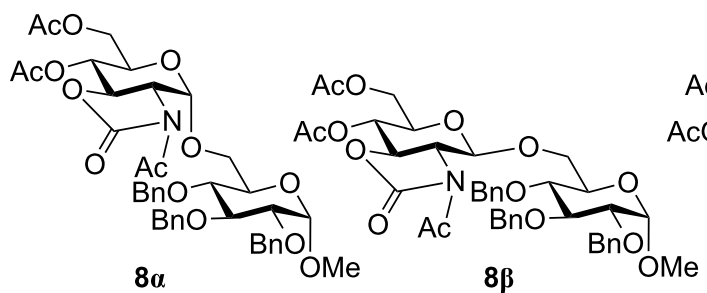

anodic

oxidation

(4 mA, $1 \mathrm{~h}$ )

$\mathrm{Bu}_{4}$ NOTf

$\mathrm{CH}_{2} \mathrm{Cl}_{2}, T$

(carbon anode)

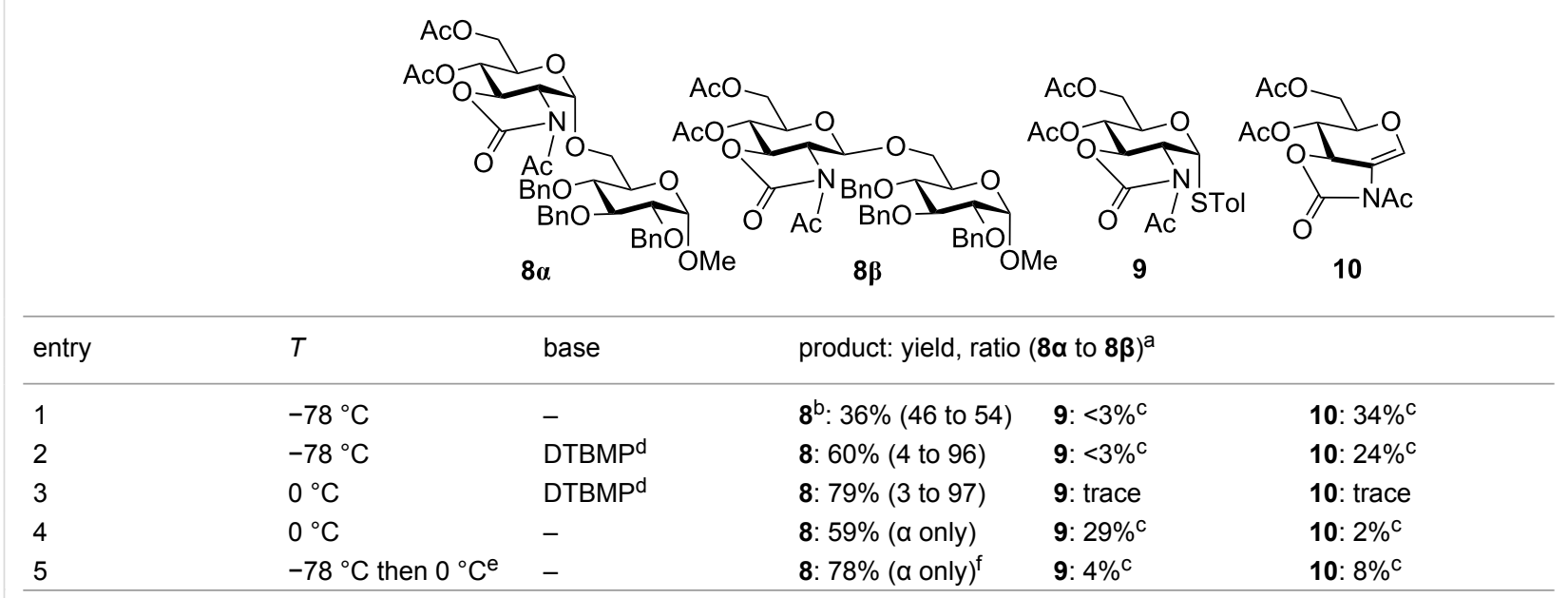

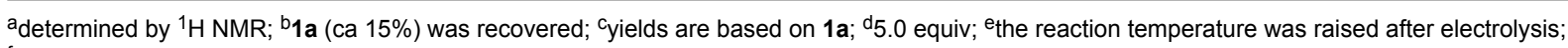
1a (ca 6\%) was recovered. 


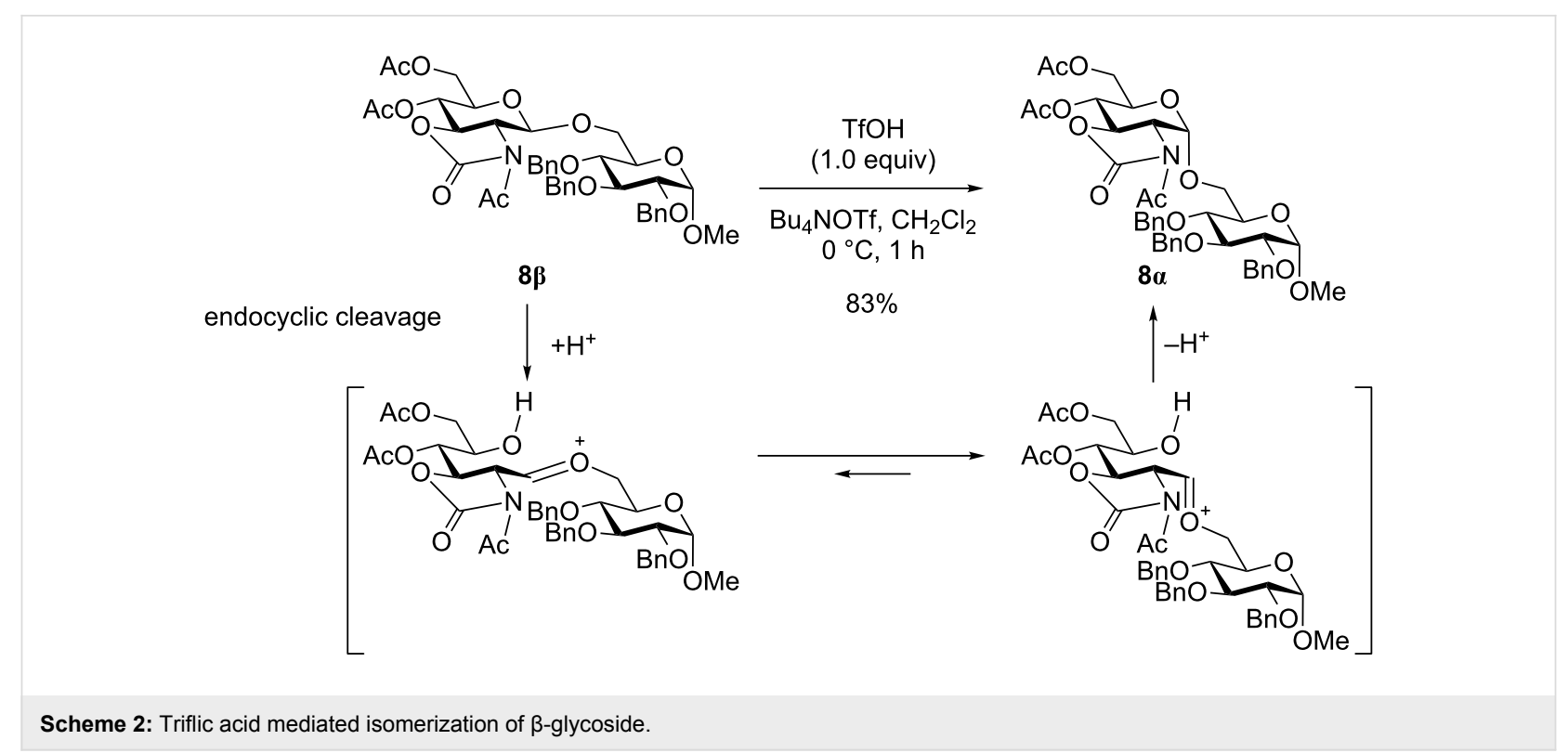

\section{Conclusion}

In conclusion, we have achieved the electrochemical generation and accumulation of glycosyl triflates equipped with the 2,3oxazolidinone protecting group. This glycosyl triflate intermediate reacted with alcohols of high reactivity to afford $\beta$-glycosides as kinetic products. The $\alpha$-products were also obtained at elevated temperatures after anomerization of the $\beta$-products, as both Oscarson and our group have previously reported [18,22-24]. Namely, $\alpha$ - and $\beta$-glycosides were obtained from 2,3-oxazolidinone donors by changing the reaction conditions. Further investigations to reveal the scope and limitations of the glycosylation reaction using electrochemically generated glycosyl triflates are in progress in our laboratory.

\section{Supporting Information}

\section{Supporting Information File 1}

Experimental procedures, spectral data of glycosyl triflates and new compounds, and ${ }^{1} \mathrm{H}$ - and ${ }^{13} \mathrm{C}$ NMR spectra.

[http://www.beilstein-journals.org/bjoc/content/ supplementary/1860-5397-8-52-S1.pdf]

\section{Acknowledgements}

This work was financially supported in part by the Grants-inAid for Scientific Research on Innovative Areas (No. 2015) from the MEXT. S. M. thanks Grants-in-Aid for Scientific Research (C) from JSPS (grant number 21590036) and Ms. Akemi Takahashi for her technical assistance. T. N. thanks Meiji Seika Kaisha, Ltd. Award in Synthetic Organic Chemistry. The authors thank Dr. Keiko Kuwata and Ms. Sakiko Goto for MS analyses.

\section{References}

1. Long, S. R. Plant Cell 1996, 8, 1885-1898. doi:10.1105/tpc.8.10.1885

2. Raetz, C. R. H.; Whitfield, C. Annu. Rev. Biochem. 2002, 71, 635-700. doi:10.1146/annurev.biochem.71.110601.135414

3. Werz, D. B.; Ranzinger, R.; Herget, S.; Adibekian, A.; von der Lieth, C.-W.; Seeberger, P. H. ACS Chem. Biol. 2007, 2, 685-691. doi:10.1021/cb700178s

4. Hu, Y.-P.; Lin, S.-Y.; Huang, C.-Y.; Zulueta, M. M. L.; Liu, J.-Y.; Chang, W.; Hung, S.-C. Nat. Chem. 2011, 3, 557-563. doi:10.1038/nchem.1073

5. Petitou, M.; von Boeckel, C. A. A. Angew. Chem., Int. Ed. 2004, 43, 3118-3133. doi:10.1002/anie.200300640

6. Banoub, J.; Baullanger, P.; Lafont, D. Chem. Rev. 1992, 92, 1167-1195. doi:10.1021/cr00014a002

7. Paulsen, H.; Koláŕ, Č.; Stenzel, W. Chem. Ber. 1978, 111, 2358-2369. doi:10.1002/cber.19781110630

8. Lemieux, R. U.; Ratcliffe, R. M. Can. J. Chem. 1979, 57, 1244-1251. doi:10.1139/v79-203

9. Benakli, K.; Zha, C.; Kerns, R. J. J. Am. Chem. Soc. 2001, 123, 9461-9462. doi:10.1021/ja0162109

10. Kerns, R. J.; Zha, C.; Benakli, K.; Liang, Y.-Z. Tetrahedron Lett. 2003, 44, 8069-8072. doi:10.1016/j.tetlet.2003.09.058

11. Wei, P.; Kerns, R. J. J. Org. Chem. 2005, 70, 4195-4198. doi:10.1021/jo047812o

12. Boysen, M.; Gemma, E.; Lahmann, M.; Oscarson, S. Chem. Commun. 2005, 3044-3046. doi:10.1039/b503651h

13. Manabe, S.; Ishii, K.; Ito, Y. J. Am. Chem. Soc. 2006, 128, 10666-10667. doi:10.1021/ja062531e

14. Manabe, S.; Ishii, K.; Ito, Y. J. Org. Chem. 2007, 72, 6107-6115. doi:10.1021/jo070669p

15. Geng, Y.; Zhang, L.-H.; Ye, X.-S. Chem. Commun. 2008, 597-599. doi:10.1039/b712591g

16. Geng, Y.; Zhang, L.-H.; Ye, X.-S. Tetrahedron 2008, 64, 4949-4958. doi:10.1016/j.tet.2008.03.103

17. Manabe, S.; Ishii, K.; Ito, Y. Trends Glycosci. Glycotech. 2008, 20, 187-202. doi:10.4052/tigg.20.187 
18. Olsson, J. D. M.; Eriksson, L.; Lahmann, M.; Oscarson, S.

J. Org. Chem. 2008, 73, 7181-7188. doi:10.1021/jo800971s

19. Geng, Y.; Ye, X.-S. Synlett 2010, 2506-2512.

doi:10.1055/s-0030-1258557

20. Manabe, S.; Ishii, K.; Ito, Y. Eur. J. Org. Chem. 2011, 497-516.

doi:10.1002/ejoc.201001278

21. Manabe, S.; Aihara, Y.; Ito, Y. Chem. Commun. 2011, 47, 9720-9722. doi:10.1039/c1cc13172a

22. Manabe, S.; Ishii, K.; Hashizume, D.; Koshino, H.; Ito, Y. Chem.-Eur. J. 2009, 15, 6894-6901. doi:10.1002/chem.200900064

23. Manabe, S.; Ito, Y. Tetrahedron Lett. 2009, 50, 4827-4829. doi:10.1016/j.tetlet.2009.05.119

24. Satoh, H.; Manabe, S.; Ito, Y.; Lüthi, H. P.; Laino, T.; Hutter, J. J. Am. Chem. Soc. 2011, 133, 5610-5619. doi:10.1021/ja201024a

25. Crich, D. J. Org. Chem. 2011, 76, 9193-9209. doi:10.1021/jo2017026

26. Nokami, T.; Shibuya, A.; Tsuyama, H.; Suga, S.; Bowers, A. A.; Crich, D.; Yoshida, J.-i. J. Am. Chem. Soc. 2007, 129, 10922-10928. doi:10.1021/ja072440x

27. Nokami, T.; Shibuya, A.; Yoshida, J.-i. Trends Glycosci. Glycotech. 2008, 20, 175-185. doi:10.4052/tigg.20.175

28. Nokami, T.; Tsuyama, H.; Shibuya, A.; Nakatsutsumi, T.; Yoshida, J.-i. Chem. Lett. 2008, 37, 942-943. doi:10.1246/cl.2008.942

29. Nokami, T.; Shibuya, A.; Manabe, S.; Ito, Y.; Yoshida, J.-i. Chem.-Eur. J. 2009, 15, 2252-2255. doi:10.1002/chem.200802293

30. Nokami, T.; Nozaki, Y.; Saigusa, Y.; Shibuya, A.; Manabe, S.; Ito, Y.; Yoshida, J.-i. Org. Lett. 2011, 13, 1544-1547. doi:10.1021/ol200242u

31. The observed stereoselectivity was determined kinetically; however, the possibility of the isomerization of the $\beta$-isomer to the thermodynamically more stable $\alpha$-isomer cannot be excluded.

\section{License and Terms}

This is an Open Access article under the terms of the Creative Commons Attribution License (http://creativecommons.org/licenses/by/2.0), which permits unrestricted use, distribution, and reproduction in any medium, provided the original work is properly cited.

The license is subject to the Beilstein Journal of Organic Chemistry terms and conditions:

(http://www.beilstein-journals.org/bjoc)

The definitive version of this article is the electronic one which can be found at: doi:10.3762/bjoc. 8.52 